\title{
Mode switching: the state, market, and anti-Covid-19 shadow of socialism in China
}

\author{
Hairong $\operatorname{Yan}^{1}$ \\ Published online: 1 September 2020 \\ (C) Springer Nature B.V. 2020
}

"Olympic Blue" was a neologism that emerged in 2008, when China hosted the Olympic Games. While Beijing had normally been smoggy, in the days leading to the Olympic Games, concerted efforts were made to reduce air pollution, including shutting down or moving polluting enterprises out of Beijing and reducing the number of motor vehicles on the road. These efforts resulted in bringing out exceptionally blue and clear skies for the Olympic Games. This practice was repeated in 2014 when China hosted an APEC meeting. Residents in Beijing teased that this interlude was "APEC Blue." Another interlude called "Parade Blue" came in 2015 when Beijing organized a parade to mark the 70th anniversary of the World War II victory. The everydayness of smoggy air was punctuated by transient blessings of eventful blue.

"Olympic Blue" flashes to mind when I recall how the Chinese state mobilized a tremendous and effective "people's war" against Covid-19 by suspending the usual market logic in healthcare, offering free provision of healthcare and launching social mobilization for social distancing. Let me briefly recall the train of key events. On Dec. 30, 2019, China's National Health Commission learned about cases of new pneumonia of unknown causes emerging in Wuhan and stepped in to investigate. The next day, China's CDC reported 27 such cases to WHO. On January 11, Chinese researchers published the virus's gene sequence on open platforms. On January 19, human-to-human transmission was confirmed publicly for the new coronavirus, displacing the earlier medical judgment of limited human-to-human transmission. At midnight of January 22, an unprecedented measure was announced to lock down Wuhan, a city with 11 million people, with lockdown beginning at 10 am the next day. Soon lockdown was extended to the entire Hubei province with 56 million people. Two days later, when 1975 cumulative cases and cumulative 56 deaths were reported in China, almost all provinces in China initiated the highest level of public health emergency. The prominent medical journal The Lancet commented about these efforts that "By most accounts, Chinese authorities are meeting international standards and isolating suspected cases and contacts, developing diagnostic and treatment procedures, and implementing public education campaigns" (Lancet

Hairong Yan

ssyhr@polyu.edu.hk

1 Department of Applied Social Sciences, Hong Kong Polytechnic University, Hong Kong SAR, China 
2020). Around the world then, Malaysia, Singapore, and France each reported three cases; Japan, South Korea, the US, and Vietnam each reported two cases; and Nepal and Australia each reported one case (Weisheng 2020).

During the Wuhan lockdown, two new makeshift hospitals for treating Covid-19 patients in the city-named Thunder God Mountain and Fire God Mountain - were constructed, with 1600 beds and 1000 beds, respectively, within 15 days. Nationally, tens of millions watched online the live aerial view of their construction progress, giving rise to the neologism "cloud inspectors" (yun jiangong). Other facilities, such as stadiums and exhibition halls, were also converted to makeshift hospitals. As the hardware infrastructure were being built, 346 teams consisting of 42,600 medical staff ( 28,000 women), sent by public hospitals of other provinces, arrived to join the Hubei local medical force to treat Covid-19 patients (Renmin Ribao 2020). More than 500,000 volunteers were active in meeting the needs of house-bound residents during the Hubei lockdown (Hubei Ribao 2020). On March 25, Hubei (except Wuhan) was unlocked, after 20 consecutive days of zero new cases; on April 8, after 76 days of confinement and 21 days of nearly continuous zero new cases, Wuhan was unlocked (National Health Commission 2020). Medical teams, who fought against Covid-19 in Hubei, were given inventive receptions as heroes upon returning to their own localities. For example, Jilin's medical teams were honored by being flown back on a chartered flight, being chauffeured in Red Flag cars - the brand usually used for driving state guests, being escorted by motorcycle police, being led through a triumphal arc of water dragons created by the fire brigade, to a ceremony presided over by the top provincial leader. Video clips of medical teams leaving Hubei and having receptions in their own localities, often shot with cell phones, went viral on social media. A netizen put together a 20-min-long collation, and it watched 20 million times and forwarded 140,000 times within 3 days (guancha.cn 2020).

With 59 Covid-19 cases and 3 deaths per million population as of late August (Worldometer 2020), the Chinese mainland now has by and large eased back into business as usual. Like the ephemeral "Olympic Blue," the eventful mode of business suspension has now passed into the everyday mode of business as usual. Facing the highly uncertain global economy and geopolitical relationship, the central leadership of Chinese Communist Party reasserts the importance of socialism while pushing for further marketization and liberalization of the healthcare system and the economy. Shortly after the ebbing of the epidemic, some public hospitals face privatization (Chaosi 2020).

Code switching refers to practices of switching between languages in conversations or even in one sentence. I venture that the practices of switching between the eventful mode of business suspension and everyday mode of business as usual and of speaking of socialism and the market economy at the same time may be considered a form of code and mode switching.

Code switching is a speech performance that demonstrates linguistical versatility and likely an embracement of multiple identities. What might mode switching tell us? Does it tell us that the Chinese state is like a super switchman who operates switches between rails or modes with trained dexterity along a predestined route? How did ordinary people deal with mode switching in the pandemic? How did Covid-19 patients and medical professionals cope with mode switching? If the time of Covid-19 in China highlighted socialism, can people in the post Covid-19 time smoothly return to business as usual? To fully answer these questions would require more in-depth research and analysis. In this essay, I offer my own preliminary observations and reflections. 
I begin my reflection with 1978, when China's healthcare system was regarded by the World Health Organization as the model global primary care initiative for developing countries (Chen 2004, 465). Then, Chinese medical expenses had less than 20\% come from selfcontribution, $1 / 3$ from the government, and the rest from one's rural collective or urban enterprise, which also covered 50\% expenses of one's dependents (Li 2014a). The first day of 1979 saw the Minister of Health propose that "Healthcare should be conducted according to economic logic" (Cao and $\mathrm{Fu} 2005)$. From then on, debates have accompanied the reform in China's healthcare system. Within the Ministry of Health, seven articles emerged later that year to contest the idea of "economic logic." The end of the 1970s was also the beginning of the rural reform, which decollectivized rural communes (Yan et al. 2020). The urban enterprise reform and the healthcare reform were launched around 1985, following the same principle of introducing economic incentives and encouraging entrepreneurship. With the collapse of rural collectives and market orientation of state-owned enterprises (SOEs), healthcare was greatly undermined by reductions in both state input and rural collective/urban enterprise contributions. Moreover, healthcare faced the pressure of subsumption to the same market dynamics that were engulfing Chinese SOEs. When the majority of SOEs were allowed to privatize in the 1990s, healthcare encountered further reform pressure and opportunities, as some officials anxiously urged, "If we wait for another one or two years, businesses will be developing elsewhere and we won't be able to keep our own turf" (Cao and Fu 2005). Not all shared this view and contention within the healthcare system again simmered and openly exploded in May 1993. The core of the contention was whether the healthcare system should be market-led or government-led. However, throughout the 1990s, voices for the market dominated the field. Local governments, hospital managements, and investors each had their own motivations in marketizing healthcare and even privatizing public hospitals.

By 2000, most peasants in China had no medical insurance, and two-thirds of rural clinics could not properly function ( $\mathrm{Li}$ and Chen 2012). Medical expenses had become a crushing burden, with self-contribution accounting for $60 \%$, collectives/enterprises providing $25 \%$, and the state $15 \%$ for medical expenses (Cao and Fu 2005). The 2003 SARS epidemic created a public health crisis, which served as the turning point that shifted China's healthcare reform. The two sides of the contention were locked in stalemate for the next 2 years. Eventually, the new central government leadership, whose administration began in the trying year of SARS, decided in 2006 that healthcare should be government-led. By then, social discontent about healthcare was raging. A survey by the National Bureau of Statistics showed that the Chinese public regarded "medical problems" as the top social well-being issue in China (Guojia tongjiju 2007). The new healthcare reform had the World Bank, the WHO, McKinsey \& Company, and Chinese citizens - who contributed over 28,000 suggestions - participating in policy formulation (Li 2014a). The new reform was launched in 2009, and from then on, state finance for healthcare grew 30\% annually (Li 2014b). Medical insurance coverages-for urban employees, urban residents, and rural residents-grew from $15 \%$ in 2000 to $95 \%$ in 2011 (Li and Chen 2012).

Yet, it is questionable in what way healthcare in China from then on has been governmentled (zhengfu zhudao). In the post-SARS healthcare reform, increased state input in healthcare-which grew 16 times in value from 2003 to 2016 ( $\mathrm{Li} 2017$, 74)-has actually fed the highly marketized and increasingly privatized medical-industrial complex, with pharmaceuticals and supplies making profits through price hikes and overmedication. Fifty percent or more of state input has gone to medical insurance, much of which is passed onto the medical-industrial complex (Li 2014c). Hence, most Chinese experience little positive impact 
of the new healthcare reform, and despite insurance, they see the amount of self-contribution continue to rise. Their distress was dramatically represented in Dying to Survive (wo bushi yaoshen), a 2018 dark comedy about a Chinese leukemia patient smuggling cheap but unlicensed cancer medicine from India for desperate fellow cancer patients who cannot afford the prescription medicine. Based on a real story in China, the film was such a national hit that it moved China's Premier to order zero tariff for cancer medicine imports (Zhongguo Zhengfuwang 2018). Yet, the Chinese government had previously issued more than 20 orders to lower the prices of medicines, without producing real structural impact. Without addressing the systemic problem of the medical-industrial complex, administrative orders often have fragmentary and transient effect. Therefore, even the Premier's order, helpful in a way, is like a cup of water that cannot extinguish the cartload of firewood in flames.

If SARS and Covid-19 are unpredictable "black swan" events, then medical marketization has been a "gray rhino." The SARS and Covid-19 epidemics have exposed how healthcare's subsumption to market logic creates systemic crippling of disease prevention. In the 2003 SARS outbreak in Taiwan, society was filled with panic and fragmented by exclusions: SARS patients were refused by neighborhoods, bodies of SARS victims were not accepted by funeral service workers, residents protested against establishing SARS clinics in their districts, etc. To respond to the SARS panic, scholar-activist Chen Meei-hsia founded the Taiwan Association for Promoting Public Health and called attention to the crippled infrastructure for disease control and prevention. Since the 1980s marketization of healthcare in Taiwan, both government policy and market dynamics have pushed healthcare to shift from prevention to treatment. While medical treatment and medicalization experienced fast expansion and corporatization, the prevention sector received a meager $3 \%$ of government funding and suffered from brain drain (Chen 2020b). A similar shift is found in Chinese mainland. Although the SARS outbreak had alerted the mainland's central government to the importance of disease prevention, its attention span was short-lived. The staff for disease control and prevention in 2020 is even smaller than during the SARS crisis, with 1.35 staff per 10,000 population, compared with the 1.75 required by the government, 9.3 in the USA and 13.8 in Russia (Li and Yu 2020, 69).

Apart from crippling disease control and prevention, medical marketization has also deformed the tiered medical care structure. For decades, top-tiered hospitals have been running at full or over-capacity, while lower-tiered hospitals and community health centers and clinics have had difficulties in attracting patients. In the context of market competition, top-tired hospitals easily siphon off patients and expand their services. Community health centers were left struggling to make ends meet, further reducing their capacity. Not surprisingly, in the early phase of the Covid-19 outbreak in Wuhan, top-tiered hospitals in Wuhan were exceedingly overwhelmed by huge numbers of anxious people who, shaken by uncertainty, resorted to the best resources for diagnosis. Cross-infection took place in the crowded environment and long lines — with waiting time as long as 7-8 h (Lao Tian 2020; Li 2020b).

Medical marketization, through commodification and without privatization, has subsumed public hospitals to market logic. Public hospitals deliver $80 \%$ of healthcare services in China, but since 1990, public hospitals have had less than $10 \%$ of their revenue from state contributions and have had to commodify their services for income generation (Chen 2020a, 2020b; Li $2010,41)$. In the process, public hospitals have become agentic in producing disparities between top-tiered and lower-level hospitals and within hospitals - with department directors having earnings 10 times those of entry level medical staff ( $\mathrm{Li}$ and Jiang 2014). In the context of medical marketization, public hospitals are coupled with the corrosive medical-industrial 
complex and are at the forefront of sometimes violent patient-doctor disputes ( $\mathrm{Li}$ and Jiang 2014; Xiao 2020; Li 2014a; Li and Chen 2012, 203-2014).

The post-SARS healthcare reform has managed to build nationwide medical insurance coverage, but has not addressed the key problem of public hospitals' subsumption to market logic and has not attempted to delink public hospitals from the medical-industrial complex. Three kinds of obstacles are making the healthcare reform difficult: lukewarm responses from local governments to the central government, as local governments are reluctant to shoulder the fiscal responsibilities for healthcare reform; obstacles presented by the medical-industrial complex; and local innovative experiments not receiving strong enough support from the central government (Li and Chen 2012, 113-114). At the central government level, insurance, pharmaceuticals, and medical treatment are overseen by different departments, each having its own interests. Altogether sixteen national-level departments have linkages with healthcare, without one coordinating the healthcare reform. Li Ling, an eminent scholar of public health in China, observes that "The interests of government departments are in sharp conflict and difficult to coordinate... Therefore, a reform of public hospitals needs a reform of the government" (Li 2014d, 2017, 74-75).

Not only is public hospitals' subsumption to market logic not addressed, but a number of government departments are joining hands to push for greater marketization. In June 2019, ten government departments jointly issued a national policy to restrict the number of public hospitals and to open space for private initiatives. Restriction of public hospitals has been underway for some years, with visible effect. From 2013 to 2018, the number of public hospitals declined from 13,396 to 12,032 , with 270 public hospitals disappearing each year. By 2015, the number of private hospitals exceeded the number of public hospitals, and between 2015 and 2018, the number of private hospitals increased at 2153 per year (21 Shiji 2019). Currently, private hospitals account for $64 \%$ hospitals nationally. In Wuhan, private hospitals were already $73 \%$ of the total in 2017 ( $\mathrm{Li} \mathrm{2020b}$ ). What has been perceived by the public is that healthcare, along with education, housing, and elderly care, have been the "four big mountains," recalling the "three mountains" once used by Mao Zedong for the older oppression experienced by Chinese people-imperialism, feudalism, and bureaucratic capitalism.

What has been demonstrated above is that the everyday mode of business as usual is a mode of continued medical marketization, accompanied by state fragmentation rather than state cohesion. It was the Covid-19 outbreak that enabled state cohesion for crisis mobilization and for the suspension of business as usual. The key decisions, such as Wuhan lockdown, free treatment of Covid-19 patients (announced on January 22), construction of makeshift hospitals, and mobilization of medical teams from other provinces to aid Wuhan, came from the central leadership. Chaos and individual mobility did continue in the city for some days even after the Wuhan lockdown on January 23. Hospitals continued to be flooded and overwhelmed by visitors, many of whom were seeking diagnosis. On February 10, 18 days after the beginning of the Wuhan lockdown, a community lockdown was imposed, in order to isolate and break the chain of transmission. More than 40,000 cadres and party members came down to the neighborhood level to coordinate supplies to Wuhan's 3000 or so communities. By February 25, Wuhan had 48 hospitals - including two new makeshift hospitals and those converted from stadia and exhibition halls - and 24,000 beds, specially designated for treating Covid-19 patients. It was not until then that the city was able to fully implement the central government's policy: all suspected and confirmed patients should be admitted to the hospital; all 
confirmed patients should be treated. It was not until then that the city was able to contain the source of infection (Lao Tian 2020).

Videologs, diaries, and firsthand accounts from some medical team members about their work experience in Wuhan have had viral circulation on social media. Against the longstanding context of doctor-patient tension, the suspension of business as usual means that medical staff now worked in a de-commodified context. These accounts revealed how they volunteered to join the medical teams for Hubei, how their family members coped with their departure, their reflections on the meaning of their work, the trauma they experienced with daily loss of life, and their narration about how they had come to see everyday life in a very different light. People inside and outside Wuhan responded to their accounts and their needs. Some medical team members reported on social media that their hospital canteen was short of supplies. Volunteers in Wuhan rather quickly responded to their needs. Women medical staff very much needed diapers, pads, and period briefs because they wanted to reduce their toilet visits as much as possible, in order to save wear and tear on their protective suits. Hospital management had failed to respond to their needs. Once these came to be known through social media, online mobilization for donations quickly took place (Pan 2020). Through the fight against Covid-19, medical staff have emerged as heroes who put themselves in harm's way for the greater public good.

Trauma, loss, hope, belief, and reflection on the meaning of one's work and life are also the content of "Wuhan, Long Time No See!", a documentary produced by Takeuchi Ryo, a Japanese filmmaker and a resident of China (Ryo 2020). Released online on June 27, 2020, this hour-long film documents 10 stories of ordinary people in Wuhan. They had a variety of roles during the pandemic: a school teacher who used her drone to video document the city when people were confined to homes during the lockdown period, a Wuhan resident who owned a local Japanese restaurant, a migrant construction worker who participated in building the Thunder God Mountain Hospital, a granddaughter who lost her grandfather, etc. Among them is Gong Shengnan, a lively young nurse who found the Covid-19 experience a turning point of her life and work. Prior to the epidemic, she was thinking about quitting her job, as she was not sure what she was doing in her life. Yet on January 21, she volunteered to work in the frontline and wrote in her microblog account that day:

This is my fifth year working as a nurse and I have never been more proud of myself - I just volunteered to work in the frontline to battle Covid-19. After coming off work, I received phone calls from friends, relatives and my supervisor, who expressed their regards for me. I cannot hold my tears back. I'm not afraid. I believe that our efforts will have paybacks.

Gong's work in the frontline was to provide emotional comfort to Covid-19 patients. When she was interviewed in April for the film and asked about how she felt about her work, the lively woman went silent and broke into tears. It was still too emotionally overwhelming for her to speak about coronavirus victims passing away.

Covid-19 patients who received treatment in makeshift hospitals also used their cellphone videos to document their experiences. Patients in makeshift hospitals were provided free food and lodging and free treatment. Compared with the outside where people were tense and on guard about social distancing, the mood seemed more relaxed in these makeshift hospitals. Some patients read, some listened to music, and still some created a skit "Down with Coronavirus" to entertain themselves. When people in China could not have public-square dancing, due to the epidemic breakout, patients and medical staff danced inside the makeshift 
hospitals. Some patients enjoyed their collective egalitarian life there so much that they were reluctant to leave when they were discharged. Some have invented the terms "fang cang wenhua" (fangcang culture) and "fangcang gongshe" (fangcang commune)-fangcang being the Chinese term for makeshift hospitals. Some commentators regard fangcang culture as a practice of socialism as it should be (Chen 2020a, 2020b; Guo 2020).

As Chinese society has gradually returned to business as usual since April, was market suspension in the battle against Covid-19 a transient anti-Covid blue? What are the meanings of such collective and individual experiences and memories which are still emotionally potent? In May 2020, a public hospital in a prefecture-level city in Jiangsu province was facing complete privatization, and the pictures of its medical staff launching open protests went viral on Chinese social media (Chaosi 2020). Given how much public hospitals have just contributed to the national effort against Covid-19, this case of privatization seems especially scandalous. More marketization is still on the way. The Ministry of Human Resources and Social Security is reportedly discussing further reform measures to transform permanent positions in the medical profession and tertiary education to contract positions (Li 2020a). Yet, hundreds of millions in China have seen how the medical staff of public hospitals have made pivotal contributions to the fight against Covid-19, while private hospitals barely made an impact. More critical reflections have surfaced. Zeng Guang, Chief Scientist of China's $\mathrm{CDC}$, commented that the 10 years of healthcare reform is 10 years of decline in public health (Zeng 2020).

The 2003 SARS crisis was a new beginning point for China's healthcare reform debate. It took 6 years of struggle before the healthcare reform took a turn in 2009 to build a nationwide medical insurance coverage. Will the 2020 Covid-19 crisis be a new beginning point? After 2008's "Olympic blue," 2014's "APEC blue," 2015's "Parade blue," etc., Beijing residents, after years of popular discontent, now in fact have more days of clear blue sky a year than before (Qain 2019). Perhaps even transient blue has a role in lighting up the way to realize a hope.

\section{References}

21shiji jingji baodao. 2019. Shi buwei yankong gongli yiyuan shuliang, jin 5nian yi xiaoshi 1300 duo jia (Ten departments strictly restrict the number of public hospitals. More than 1300 have disappeared), Guancha.cn, June 14, https://www.guancha.cn/politics/2019_06_14_505599.shtml

Cao Haidong and Fu Jianfeng. 2005. Zhongguo yigai 20nian: zaici zhan zai shizi lukou (Twenty years of China's healthcare reform: at the crossroad again). Nanfang zhoumo (Southern Weekend), August 4, A06.

Chaosi. 2020. Xuzhoushi sanyuan bei siyouhua, women liaoliao saying yiyuan haochu dou you sha (No. 3 hospital in Xuzhou faces privatization. Let's talk about the good of private hospitals). Xinchao chensi lu, May 24, https://mp.weixin.qq.com/s/_xu_xUsfT0674H5bP-IqBg

Chen, M.S. 2004. The great reversal: Transformation of health care in the People's republic of China. In The Blackwell Companion to Medical Sociology, ed. William C. Cockerham, 2nd ed. Oxford: Blackwell.

Chen, M.S. 2020a. Hengxing liang'an de gongwei yiliao shichanghua (marketization of public health sweeping across the strait), Renmin shiwu zhuquanwang (People's food sovereignty Net), April 14, http://www. shiwuzq.org/portal.php? $\bmod =$ view\&aid=2237

Chen, M.S. 2020b. Yiqing mianqian, women de gongwei xitong weihe ruci cuiruo? (in front of the epidemic, why is our public health system so fragile?) Renmin shiwu zhuquan (People's food sovereignty Net), January 26, http://www.shiwuzq.org/portal.php?mod=view\&aid=2129

Guancha.cn. 2020. Yingxiong kaixuan! Gedi zuigao liyu yingjie yingxiong huija (Triumphant return! All places treat heroes return with the highest level of honor), Guancha.cn, March 23, https:/www.guancha. cn/politics/2020_03_23_543325.shtml 
Guo Songmin. 2020. Yiyuan nei keyi tiao guangchangwu, biaoyan Xiaopin?: lun fangcang yiyuan de shehuixue yiyi (Public square dance and skit performance in hospitals?: On the sociological significance of make-shift hospitals). Duli pinglunyuan Guo Songmin (Independent Commentator Guo Songmin), Feb 25, http://www. shiwuzq.org/portal.php?mod=view\&aid=2162

Guojia tongjiju (National Bureau of Statistics). 2007. 2007nian quanguo qunzhong anquangan diaocha zhuyao shuju gongbao (report on nation-wide survey of people's sense of security). http://www.stats.gov. cn/tjjj/tjgb/qttjgb/qgqttjgb/200801/t20080108_30634.html

Hubei ribao (Hubei Daily) 2020. Ying Yong zai wuhanshi tiaoyan zhiyuanzhe fuwu gongzuo weiwen zhiyuanzhe daibiao (Ying Yong investigates volunteer service work in Wuhan and gives his goodwill) . Zhongguo gongchandang xinwenwang (CPC News), March 5, http://cpc.people.com.cn/BIG5/n1/2020 /0305/c117005-31618688.html

Lao Tian. 2020. Wuhan yiqing qinli ji: Yiwei shi heitian'e, qishi shi huixiniu (personal experience of the Wuhan epidemic: I thought it was black swan, but it is gray rhino), Renmin shiwu zhuquan wang (People's food sovereignty Net), March 15, http://www.shiwuzq.org/portal.php?mod=view\&aid=2201

Li Ling. 2010. Yigai “bei shui yi zhan” (Heathcare reform's desperate fight). Zhongguo baodao (China report): 40-41.

Li, Ling. 2014a. Zhongguo de yigai zhexie nian zuo le shenme? (what has Chinese health care reform done in these years?). Zhongguo xibu (Western China) 18: 63-65.

Li, Ling. 2014b. Xin yigai zuo le shenme, mei zuo shenme? (what has the new health care reform done and not done?). Weisheng jingji yanjiu (Health Economics Research) 10: 41-47.

Li Ling. 2014c. Zhongguo xinyigai,wenti yu defang shijian yanjiu (The profile, problems and local practices of the new healthcare reform). Zhongguo shichang (China Market) 32:52-56.

Li, Ling. 2014d. Gongli yiyuan gaige de nandian zai na'er (what is the difficult about the reform of public hospitals). Zhongguo yiliao baoxian (China Health Insurance) 8: 26.

Li, Ling. 2017. Shenme yang de gaige neng rang yiyuan bu zai zhuli (what kind of reform can stop hospitals from seeking profit). Renmin luntuan (People's Tribune) 9: 74-75.

Li Hongmei. 2020a. Quxiao bianzhi, yisheng buyong pa (Without permanent positions, doctors need not be afraid), Renminwang, August 12, http://www.clssn.com/html1/report/16/4942-1.htm

Li Ling. 2020b. Yiqing dangqian, kan Li Ling tan zhe chang yiqing de "wei” yu "ji”" (Facing the epidemic, let's see how Li Ling discusses the "risks" and "opportunities"). Guanchazhe (guancha.cn), February 11, http://www.shiwuzq.org/portal.php?mod=view\&aid=2143.

Li, Ling, and Jianfeng Chen. 2012. Xin yigai de jinzhan pingshu: Jiyu lishi shiye he quanqiu shijiao de fenxi (an evaluation of the progress of the new medical reform: An analysis from historical and global comparative perspectives). Shehui baozhang yanjiu (Social Security Studies) 1: 107-115.

Li, Ling, and Yu Jiang. 2014. Ruhe jiejue baoli shangyi wenti. Juece tansuo (Policy Research and Exploration) 6: $15-16$.

Li, Ling, and Yu Jiang. 2020. Buqi yiliao weisheng tixi duanban (make up for the shortfalls of the healthcare system). Zhongguo dangzheng ganbu luntuan (Chinese Cadres Tribune) 3: 69-72.

National Health Commission. 2020. Yiqing tongbao (Daily report on the epidemic situation). http://www.nhc. gov.cn/xcs/yqtb/list_gzbd.shtml?wYNOrhhjiR4y=1597930761053

Pan Di. 2020. Jiemei, qianxian de weishengjin he anxinku hai gou ma? (sisters on the front line, do you have enough pads and period briefs?) Zhengwu gushi (stories of Zhengwu), February 17, https://mp.weixin.qq. com/s/7OzaU66zELgP3kR59Mtasw

Qain Siwen. 2019. Beijing "zhimai” 20nian licheng: Zhuanfang qinghua daxue huanjing xueyuan yuanzhang he Kebin (twenty years of Beijing treating smog: An interview with Dean He Kebin of Tsinghua University's school of environment). United Nations News, April 16, https://news.un.org/zh/story/2019/04/1032451

Renmin ribao (People's Daily, overseas edition). 2020. 346 zhi yiliaodui 4.2wan ren dida Hubei kangyi (346 medical teams and 42000 medical staff arriving in Hubei to fight the epidemic). March 9, http://paper. people.com.cn/rmrbhwb/html/2020-03/09/content_1975139.htm

Ryo, Takeuchi. 2020. Long time no see, Wuhan. Youtube, June 26, https://www.youtube.com/watch?v=N4 ABOJ1y5iM\&list=PLxBReoeYDcrukZA_3OOkCNhXXu1pZ5VHM

The Lancet. 2020. Emerging understandings of 2019-nCov. The Lancet 395(10221): 311, https://www.thelancet. com/journals/lancet/article/PIIS0140-6736(20)30186-0/fulltext

Weisheng jiankangwei (National Health Commission). 2020. Jiezhi yi yue 25ri 24shi xinxing guanzhuang bingdu ganran de feiyan yiqing zuixin qingkuang (the latest situation about pneumonia infection of a new coronavirus up till 24 hours of January 25), January. 26, http://www.gov.cn/xinwen/2020-01/26 /content_5472228.htm

Worldometers. 2020. Reported cases and deaths by country, territory, or conveyance. Worldometer, accessed August 22, 2020, https://www.worldometers.info/coronavirus/ 
Xiao Wu. 2020. Yiliao tixi de wenti qizhi "Putianxi" (the problems with the healthcare system are not limited to the "Putian" faction). Renmin shiwu zhuquan wang (People's food sovereignty Net), February. 24, http://www.shiwuzq.org/portal.php?mod=view\&aid=2159

Yan, Hairong, Ku Hok Bun, and Xu Siyuan. 2020. Rural revitalization, scholars, and the dynamics of the collective future in China. Journal of Peasant Studies. https://doi.org/10.1080/03066150.2019.1694911.

Zeng Guang. 2020. Yigai 10 nian shiji shi gonggong weisheng huapo de 10 nian (the ten years of healthcare reform is the ten years of healthcare deline). Fenghuang wang (ifeng.com), May 10, https://mp.weixin.qq. com/s/q0O1OMaKiKCR8NdDN5uyXA

Zhongguo zhengfuwang (Chinese Government Net). 2018. Li Keqiang jiu dianying "Wo bushi yaosheng" yin reyi zuo pishi (li Keqiang gave his instruction about film "dying to survive" being a hot topic), zhongguo zhengfu (Chinese government), July 18, http://www.gov.cn/guowuyuan/2018-07/18/content_5307223.htm

Publisher's note Springer Nature remains neutral with regard to jurisdictional claims in published maps and institutional affiliations. 